\title{
KAGAN VE KATUN
}

\author{
Doç.Dr. S.GÖMEÇ*
}

Türk devlet teşkilatının ilk şekillerinin Hun devlet yapısında görüldügü bir gerçektir. Ancak biz Hunlara ait bilgileri yabancı kaynaklardan, özellikle Çin ve Roma menşeili kayıtlardan ögrenebiliyoruz. Bunun yanısıra Türklerle ilgili ilk Türkçe belgeler Kök Türk harfleriyle yazılmış olan abidelerdir. Biz bu makalede Kök Türkçe kaynaklara bağlı olarak eski Türk devletini idare eden Kagan ve Katun hakkında bilgiler vermeye calışacağız. Kök Türk ve Uygur devletlerinde, devletin başındaki kişi kagan unvanıyla anılmaktadır. Çin kaynaklarında K'ohan şeklinde transkripsiyon edilen bu unvanın Türkçe olmadı̆̆ı ve bir takım menşelere dayandırıldığı görülmektedir'. Menşeî ne olursa olsun, hükümdar manasına gelen bu terim Türkleşmiş ve Türk kültürünün bir unsuru olmuştur.

Tanrı tarafindan bu göreve tayin edilen Türk kaganı, bütün yeryüzünün, yani insanlığın hükümdarıdır. Türk hakimiyet anlayışının bir tezahürü olan bu düşünce Kök Türkçe yazıtlara da aksetmiştir: Üze Kök Tengri asra yağız yer kılındukda ikin ara kişi oğłı kılınmış. Kişi oglınta üze eçüm apam Bumın Kagan, İstemi Kagan olurmış ${ }^{2}$. Türk devlet hiyerarşisine göre, kagan en tepede bulunur ve bu unvan kolay kolay alınmazdı. Herşeyden önce kaganlığın birinci şartı Türk soylu olmaktı. Öyle ki, babası Türk annesi Türk soylu olmadığı için, Türk tarihinde bazı kişilerin tahta çıkamadıklarını biz biliyoruz ${ }^{3}$. Kagan olmanın diğer bazı şartları da vardır. Bu şartları kendinde toplayan kişi kagan olabilir. Kaganlığın ilk şartı bilge ve alp olmaktadır. Kök Türk tahtına çıkan kaganlar bilge ve alp oldukları için bu makama çıkabilmişlerdir: Bilge kagan ermiş, alp kagan ermiş ${ }^{4}$. Kaganı alp ermiş, ayguçısı bilge ermiş ${ }^{5}$. Bilgesin üçün, alpın

- A.Ü. D.T.C.F. Tarih Bolúmü

'L. Rasonyi, Tarihte Türkııık, 2. Baskı, Ankara 1988, s.60; B. Ógel, Türk Kültürünün Gelişne Gaglari, 3. Baskı, Istanbul 1988, s.578; A Caferoglu, "Tukyu ve Uygurlarda Han Unvanları", Türk Hukuk ve Iktisat Tarihi Mecmuası, C.I. Istanbul 1931, s.106; P.A. Boodberg, "The Language of the To-pa Wei". Harvard Journal Asiatic Studies. Vol. I, 1936, s.171; K. Shiratori, "Kaghan Unvanının Menşei", Gev. I. Gobkbakan, Belleten, C.9, Ankara 1945, s.499504: P. Olbricht, "Uchida`s Prolegonena zu einer Geshichte der Jou-jan", Ural-Altaische Jalırbücher. Band 26, Wiesbaden 1954, s.96-97; B.Ogel, "Dogu Gokturkleri Hakkında Notlar", Belleten, C.21, Ankara 1957, s.130.

${ }^{2}$ Bakınız, Kb! Tigin Yazıtı, Dogu tarafı, 1. Satır; Bilge Kagan Yazıtı. Dogu tarafi, 2-3. Satır: Yukarıda mavi gok, aşağıda yağız yer yaratıldıkta, ikisinin arasında insan oğlu yaratılmıs. Insan oglununizerine atalarım Bumın Kagan ve Istemi Kagan oturmus; Oturduktan sonra Turk milletinin ulkesini, tơresini idare etmiş duzenlemiş

${ }^{3} \mathrm{~V}$. Minorsky, Tamim Ibn Bahr's Journey to the Uyghurs, Bruxelles 1948, s.303; M.T.Liu. Die Chinesischten zur Geschichte der Ost-Turken (T'u-küe), C.1, Wiesbaden 1958, s.4344: H.tecsedy, "Tribe and Tribal Society in the 6 th Century Turk Empire", Acta Orientalia. 25. Budapest 1972, s.251

${ }^{4}$ Bakınız, Köl Tigin Yazıtı, Doğu, 3; Bilge Kagan Yazıtı, Dogu. 4: Bilge kagan imiş. alp kagan imiş. 
üçün ${ }^{6}$. Yani kaganın bilgili ve akıllı olması yanında cesur ve yiğit de olması gerekmektedir.

Kagan olacak kişi aynı zamanda erdemli olmalıdır. Erdem, fazilet demektir. Erdemli olmayan kişi kagan olamaz. Kök Türkçe kitabelerde karşımıza en çok çıkan kelimelerden biridir. Kagan küç'lü olmalıdır: Küçlüg alp kaganımda adırulu bardıngız ${ }^{7}$. Özellikle bu unvan Uygur kaganlarının adlarında görüyoruz. Kagan olmanın bir bașka şartı külüg ${ }^{8}$ yani ünlü olmaktır. Bumın, Juan-juanları mağlûp ederek ün kazanmıştır, Bilge de ta şadłığı sırasında birçok savaşa katılarak ün almıştır. Bunun gibi Kök Türk tahtına çıkan kaganlar hep ünlưdür: Antag külüg kagan ermiş ${ }^{9}$. Bu unvan özellikle beg adlarında görullmektedir. Bunların yanısıra kaganın kut, yarlık ve ülüg gibi Tanrı tarafından verilen özelliklere de sahip olması gerekmektedir. Tabi ki, bütün bunlar kaganın yaradılışıyla da ilgilidir. İyi huylarla donatılan kaganlar milletine ve ülkesine faydalı oluyorlardı, fakat iyi huylarla yaratılmamış olan kaganlar milletini ve ülkesini felakete sürüklemektedir: anta kisre inisi eçisin teg kılınmaduk erinç, oglı kangın teg kılınmaduk erinç, biligsiz kagan olurmış erinç, yablak kagan olurmış erinç; buyrukı yime biligsiz ermiş erinç, yablak ermiş erinç. Begleri bodunı tüzsiz üçtin Tabgaç bodun tebligin, kürlügin üçün, armakçısın üçün inili eçili kingşürtükin üçün begli, bodunlıg yongşurtukın üçün Türk bodun illedük ilin ıçgını ıdmış ${ }^{10}$.

Yeni kaganın tahta çıkış töreni, Çin kaynaklarında oldukça renkli bir şekilde anlatılmıştır. Yeni kagan bir keçe ùzerine oturtularak, dokuz kişi tarafından göge kaldırılmakta, çadırın etrafında, güneş istikametinde dokuz kez döndürülmektedir. Sonra ipek bir şal ile boğazı sıkılarak kaç yıl hüküm süreceği sorulmakta ve ağzından çıkan ilk ses veya sözcủğe bakılarak bir süre tayin edilmektedir".

'Bakınız, Tunyuku Yazıtı I. Taş, Güney, 3; Dogu, 4; Kuzey, 5:Kaganı alp imis, muşaviri bilge imis.

${ }^{6}$ Bakınız, Koı İç Çor Yazıtı, Batı, 7: Bilgesi için, yigitliği, erdemliliği için.

${ }^{7}$ Bakınız, Ongin Yazıtı, Sag, 4: Guçü, yigit kaganımdan ayrıldınız.

${ }^{x}$ Drevnetyurkskiy Slovar, Redaktorı: V.M. Hadelyayev - D.M. Nasilov - E.R. Tenişev - A.M. Sçerbak, Leningrad 1969; S.G. Clauson, An Etymological Dictionary of Pre-ThirteenthCentury Turkish, xford 1972, s.717; Ögel, a.g.e., s.644; B.Ögcl, Turklerde Devlet Anlayışı, Ankara 1982, s.267.

"Bakınız, Kol Tigin Yazıı, Dog, 5-7; Bilge Kagan Yazıtı, Doğu, 5: Bu kadar unlü kagan imis.

${ }^{10}$ Bakınız, Kil Tigin Yazıtı, Dogu, 4-7: Bilge Kagan Yazıtı, Dogu, 5-7: ondan sonra kuçuk kardeşi büyuk agabeyi gibi yaratılmamıs oldugundan, oğlu babası gibi yaratılmamıs oldugundan, bilgisiz kaganlar tahta oturmuş oldugundan, kotú kaganlar tahta oturmus oldugundan; bakanları da bilgisizmiş, kơtá imiş. Beyleri, halkı duzensiz oldugu için, Çin milleti aldatıcı oldugu için, bey ve halkın arasını açtığı için Türk milletinin alkesi elinden çkmis

"W. Eberhard, Cin'in Şimal Komşuları, Çev. N. Uluğtuğ, Ankara 1942, s.87: H.N. Orkun, Turk Tarihi, C.1, Ankara 1946, s.136; F. Laszlo, "Kagan ve Ailesi", Türk Hukuk Tarihi Dergisi, 6/10-11, Ankara 1968, s.222; E. Esin, "Kun-Ay (Ay-Yıldiz Motifinin Proto-Turk Devirden Hakanlılara Kadar Ikonografisi)", VII. Türk Tarih Kongresi Bildirileri, C.1, Ankara 1972, s.329. 
Katun için de buna benzer törenler icra edilmektedir.

Kök Türkçe kaynaklarda kaganın vazifeleride dolaylı şekilde anlatılmaktadır. Kagan milletin iskânını ve sosyal teşkilatlanınasını sağlamalıdır. Bumın ve istemi Kök Türklerin başına geçtikten sonra, Türk milletinin iskânını ve düzeni sağlamışlardır. Bilindiği gibi Bumın Kagan devletin merkezinde, Ötüken'de kalırken, kardeşi ÿstemi de Batıdaki On Okların teşkilatlandırılması ile vazifelendirilmişti: İlgerü Kadırkan Yışka tegi, kirü Temir Kapıgka tegi kondurmış ${ }^{12}$. Aralarındaki sosyal intizam kaybolduğu için de, Çin'e tekrar boyun eğmek zorunda kalmışlardır: Yagı bolıp, itenü yaratunu umaduk yana içikmiş ${ }^{13}$. Fakat çok geçıneden ortaya ÿlteriş çııı, Tüıkleri birleştirerek, yeniden bir düzenleme yapmıştır: Tölös, Tarduş bodunıg anta itmiş ${ }^{14}$. Bilge de amcasının ölümünden sonra, karışıklık içerisine düşen ülkesini sosyal bír düzenleme ile tekrar diriltmiştir: Kagan olurıp, yok çıgany bodunıg kop kubratdım $^{15}$ Kitabelerde siyasî bir ad yerine geçen Türk'e dahil olan bütün kavimlere karşı aynı sorumluluk hissedildiği için, onların da k:arışıklık içerisinde bulunmamalarına özen gösterilmiş ve siyasî teşkilatlanma yapılırken onlar da göz önünde bulundurulmuştur: Kögmen yir-sub idisiz kalmazun tiyin, Az, Kırkız bodunıg itip, yaratıp keltimiz...Kadırkan Yışıg aşa bodunıg aniça konturtımız, ança itdimiz...Kara Türgiş bodun kop içikti. Ol bodunıg Tabarda konturdımız...Tengri yarlıkaduk üçün özüm olurtukıma tört bulungdakı bodunıg itdim, yaratdım ${ }^{16}$. Görüleceģi gibi Türk kaganları yeni bir ülke fethettikleri zaman, idaresi altındaki Türkleri buralara yerleştirerek, tıpkı daha sonraki yüzyıllarda olduğu üzere (mesela Anadolu'nun Türkleşmesi) kazanılan toprakları iskâna açıyorlardı. Hunlar çağından beri Orta Asya'daki Türk yerleşim bölgelerinin izlerine rastlanılması ${ }^{17}$, hep bu iskân politikaları sayesindedir. Selenge Irmağı kıyısında Moyun Çor'un, tahminen 758 yılında Bay-Balık adlı bir şehri, Sogdlu ve Çinli ustalara yaptırması, bunun en çarpıcı delilidir: Sugdak, Tabgaçka Selengede Bay Balık yapıtı birtim ${ }^{18}$.

\footnotetext{
${ }^{12}$ Bakınız, Kol Tigin Yazıtı, Doğu, 2-3; Bilge Kagan Yazıtı, Doğu. 3-4: Dợ̆uda Kadırkan Yış'a kadar. batıda Temir Kapi ya kadar (Turk millctini) yerleștirmis

${ }^{13}$ Bakınız, Köl Tigin Yazıtı, Doğu, 10: Bilge Kłggan Yazıtı. Doğu, 9: Düşman olup, düzeni saglayamadiklarından yine (Çin'e) tabi olmus.

14Bakınız. Köl Tigin Yazıtı. Doğu. 14: Bilge Kagan Yazıtı. Doğu. 12: Tolos. Tarduş halkın orada tanzim etmis.

15 Bakını\%, Kol Tigin Yazıtı, Güney, 10; Bilge Kagan Sazıtı. Kuzcy. 7-8: Kagan oturup. yoksulfakir milleti hep toplattum

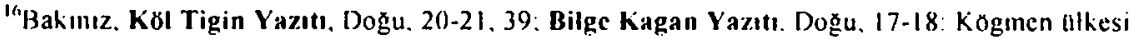
sahipsiz kalmasın diye. $A 7$ ve Kırkız halkım dizenleyip. geldik... Kadırkan $Y ı s ̧ i$ aşan kavimleri boylece yerleştirdik. boylece dizenledik... Kara Turgis halkı hep itaat etti. O halkı Tabar'da yerleştirdik. Tanıı izin verdiği için. kendim oturduğumda dört taraftaki halkı dazenledim. yarattı

${ }^{17}$ Ogel. Türk Kültürünün Gelişme..., s.344-345; B.Ögel, Islamiyetten Once Türk Kültur Tarihi, 2.baskı, Ankara 1984; s.91-364; E. Esin, İsłamiyetten Önceki Türk Kältürü Tarihi ve İslama Giriş, Istanbul 1978. s.43-136

${ }^{1 x}$ Bakınız, Sine-1lsu Yazıtı, Batı, 5: Sogdlar ve Tabgaçlara Selenge'de Bay-13alık yaptırdım
} 
Kagan kendinden sonra, devletin idarî kademesinde yer alacak olanları da tayin etmelidir. İlteriş Kagan, Ötüken'de hakimiyetini tesis ettikten sonra, kardeşi Kapgan'ı şad ${ }^{19}$, To-sifu'yu da yabgu ${ }^{20}$ tayin etmişti: Tölös, Tarduş bodunı anta itmiş. Yabgug, şadıg anta bermiş ${ }^{21}$ Bilge de, amcası Kapgan Kagan tahta çıktığında Tarduş Şad ilan edilmişti: Tengri yarlıkaduk üçün tört yigirmi yaşımka Tarduş bodun üze şad olurtım. ${ }^{22}$ Kapgan Kagan aynı zamanda küçük oğlubu İni III Kagan, kardeşi To-si-fu'yu da Sol Şad yapmıştı ${ }^{23}$. Köl Bilge Kagan da Uygur birligini sağlayınca, büyük oğlu Tay Bilge Tutuk'u 747 yılında yabgu tayin etmiştir: Tay Bilge Tutukıg yabgu atadı. ${ }^{24}$ Tay Bilge Tutuk yabgu oldugu

19 Genellikle, Tưrkçe'ye Farsçadan geçtiģi iddia edilen bu unvanın. kagandan sonra geldig̣i soylenmişse de (bakınız, H Vambery, Noten zu den Alttirkischen Inschriften der Mongolei und Sibiriens, Helsingfors 1898, s.1/4; Clauson, a.g.e., s.866; P.B. Golden, Kzahar Studies. An historico-philogogical inquiry into the origins of the Khazars. Budapest 1980, s.206; S.G. Clauson, "The Ongin Inscription", Journal of the Royal Society, London 1957, s.186; E.H. Parker, "Inscription de L'Orkhon". Journal of the China Branch of the Royal Asiatic Society, Vol.31, (1896-97) Shanghai, s. 18: Laszlo, a.g.m., s.48; S. Cagatay, "Il, Ulus ve Yonetenler", A.Ü. DTCF Cumhuriyetin 50. Yıldonnumu Anma Kitabı. Ankara 1974, s.291; B. Ögel, "Über die Altturkische Scha (Su-Baschu) Würde", Central Asiatic Journal. $8 / 1$, Wiesbaden 1963, s.27-42; A. Bombaci, "On the Ancient Turkish Title Sad", Gururjamanjarika. Studi in Onore di Giusepe Tucci, Napoli 1974, s.167-193), Cin kaynaklarında sha, she veya c'ha seklinde kaydedilen bu unvanı hukumdar ailesinden bir tiginin taşıdıgını ve kagandan sonra uçünca dereceyi işgat ettigini biliyoruz. (bakınız, Orkun, a.g.e., s.137; Clauson, a.g.e., s.866; Çagatay, a.g.m., s.291; A. Bombaci, "The Husbands of Princess Hsien-Li Bilga", Studia Turcica, Budapest 1971, s.115). Umumiyetle kagan cocukları veya yegenjeri olan şadların bağımsız ordulara sahip oldukları, fakat kaganada dogrudan bağiı bulundukları kesindir (bakınız, Ögel, Türk Kultüurünün Gelişme..., s.646: Ogel, Tük Devlet..., s.233; Çağatay, a.g.m., s.291). Bunun yanısıra, kitabelerde bir de şadapıt unvanı geçmektedir (bakınız, Köl Tigin Yazıtı, Güney, 1; Bilge Kagan Yazıtı, Guney, 13-14) ki, bu unvanın kökünün şaddan geldigi soylenmektedir (bakinız, Clauson, a.g.e., s.867; S.G. Kjlyaştornıy-V.A. Livşį̧, "The Sogdian Inscription of Bugut Revised", Acta Orientalia, 26/1, Budapest 1972, s.88). Biz de bu gơruşe katılıyoruz.

20) Yabgu unvanınin buttun Turk boylarında ve çeşitli yabancı kavimlerde gorulduga tesbit edilmiştir (bakınız, R. Grousset, Bozkır Imparatorluğu, Cev. R. Uzmen, İstanbul 1980, s.94; Rasonyi, a.g.e., s.61: Clauson, a.g.e., s.873; Laszlo, a.g.m., s.48: S.G. Clauson, "The Earliest Turkish Loan Words in Mongolian", Central Asiatic Journal, 4/3, Wiesbaden 1959. s.179). Hunlar zamanında shan-yü şeklinde gorulen bu unvanı, Batı Turkistan ve Fergana yerli beyleri de taşıyordu, daha sonra bu unvanı Kok Tarkler çagıında On Ok liderlerinde, dolayısıyla veliahtta ve Oguz, Karluk ileri getenlerinde goruyoruz (bakınız, Ogel, a.g.e., s.349; S.Seșen, Islaw Cografyacilarına Göre Tükler ve Türk Ülkeleri. Ankara 1985, s.64). Başlangıça aşağı-yukarı kagan unvaniyla eşit manaya gelen yabgu, daha sonraki yozyıllarda, kagandan bir alt dereceyi ifade etmiş ve 10 . Yuzyllara gelindiginde, boy reislerinin unvanı olmuştur (bakınız, Ögel, Türk Kütürünỉn Gelişme..., s.613: Golden, a.g.e., s.190, Laszlo, a.g.m., s.50).

${ }^{21}$ Bakınız, Kö Tigin Yazıtı, Dogu, 14; Bilge Kagan Yazıtı, Dogu, 14-15; Tólos, Tarduş halkını orada duzenlemiş. Yabguyu ve şadı orada aamıs

22 Bakınız, Koı Tigin Yazıtı, Doğu, 17; Bilge Kagan Yazstı, Dogu, 14-15; Tanrı izin verdigi için ondort yaşımda Tarduş halkı uzerine şad olarak oturdum.

23 Liu, a.g.e., s.163; J.T. Chang, T'ang Devrindeki Doğu Göktürkleri Hakkında Yeni Belgeler, Doktora Tezi, Taipei 1968, s. 166

${ }^{24}$ Bakını, Sine-Usu Yazıtı, Kuzey, 11-12: Tay Bilge Tutuk'u yabgu tayin etti. 
halde, Moyun Çor ondan daha atik davranarak, Tay Bilge'yi ortadan kaldırmış ve kendi oğullarını yabgu ve şad atamıştır: Eki oglıma yabgu şad at birtim. Tarduş, Tölös bodunka birtim. ${ }^{25}$ Aynı Moyun Çor, Tay Bilge Tutuk örneğinde olduğu gibi, Ulug Bilge Yabgu ile Bögü de mücadeleye girişmiş ve şad olan Bögü, bu mücadeleden galip çıkmıştır. Yazıtlardan da görüleceği üzere yabgular Tarduş, şadlar Tölös adıyla anılmışlardır.

Kagan. bağlı boy ve kavimlere de yöneticiler atamalıdır. Kitabelerde karşımıza çıkan enteresan bir durum da şudur: Bilge Kagan tahta oturdugu zaman, güneydeki kavimlerin üzerine sadapıt begler, kuzeydekilere de tarkanlar ve buyruklar tayin etmiştir: Tengri teg tengride bolmış Türk Bilge Kagan bu ödke olurtım. Sabımın tüketi eşidgil. Ulayu ini yigünim, oglanım, biriki uguşım, bodunım, biriye şadapıt begler, yırıya tarkat, buyruk begler, Otuz Tàtar...Tokuz Oguz begleri, bodunı bu sabımın edgüti eşid.... ${ }^{26} .752$ senesinde, Tokuz Oguz-Kırkız seferi sonunda, Moyun Çor tarafından Çiklere Tutuk $^{27}$ tayin edilmiştir: Çik bodunka tutuk birtim. ${ }^{28}$ Kaganın kendi ailesinden başlayarak, etrafındakileri çeşitli görevlere getirmesi ve onları her zaman denetlemesi, Türk devletini cihanşûmûl ve sosyal devlet anlayışından ileri gelmektedir. Türk devletinin gayesi, kendi milletinin olduğu kadar, dünyanın da nizamını sağlamaktır.

İyi bir kagan ülkesinin törelerini, yani kanunlarını da düzenlemeli ve yaymalıdır. Bumın ve istemi, kaganlığın başına geçer geçmez, ülkeyi ve töreyi düzenlemişlerdir: Kişi oglınta üze eçüm apam Bumın Kaģan, istemi Kagan olurmış; olurupan Türk bodunung ilin törüsin tuta birmiș, iti birmiş ${ }^{29}$. Bir devletin mevcudiyeti için gerekli olan şartlardan birisi de kanunlara sahip olmasıdır. Hernekadar Türk milleti kanunlarını yazılı olarak saklamadıysa da,

${ }^{25}$ Bakınız, Şine-Usu Yazıtı, Doğu, 7; Tes II Yazıtı, Batı, 6: Iki oğluma yabgu ve sad unvanı verdim. Tarduş ve Tölos halkının uzerine gonderdim.

${ }^{26}$ Bakınız, Köl Tigin Yazıtı, Güney, 1-2; Bilge Kagan Yazıtı, Kuzey, 2: Tanrı tarafından gökte yaratılmıs, Tưrk Bilge Kagan bu zamanda tahta oturdum. Sözumu bitene kadar dinle. Benden sonra gelen, küçük kardeşimden yeğenim, çocuklarım, soyum ve milletim, sağdaki (güney) sadapit begler, soldaki (kuzey) tarkanlar ve buyruk begler, Otuz Tatarlar... Tokuz Oguz begleri, halkı bu sözlumü iyi dinle...

27 Tutuk unvanının menşeinin Çince olduğu ve tu-tu şeklinde transkripsiyonu edildiği ve hem vali, hem boy beyi, hem de askeri komutan oldugu soylenmektedir (bakınız, Clauson, a.g.c., s.453; Ögel, a.g.e., s.302; H. Ecsedy, "Old Turkic Titles of Chinese Origin", Acta Orientaila, 18, Budapest 1965, s.84). Bu unvanın Türklere 558 yılından evvel geçmis olabileceği, Tibet, Hotan ve Sogd metinleri yanında, daha sonraki yüzyıllara ait uygurca metinlerde de bulundugu zikredilmekle beraber, bu unvanın Türkçe tutmak fiili ile de ilişkisi dikkate çekilmiştir (bakınız, A.V. Le Coq. Chotscho, Graz-Austria 1979, s.30; Ecsedy, a.g.m., s.85-86; K Czegledy, "Gardizi on the History of Central Asia (746-780)", Acta Orietalia, 27/3, Budapest 1973, s.259).

2* Bakınız, Sine-Usu Yazıtı, Guney, 2: Cik halkına tutuk verdim.

${ }^{29}$ Bakınız, Köl Tigin Yazılı, Dogu tarafı, 1-2. satır: Insan oglunun uzerine atalarım Bumın Kagan ve Istemi Kagan oturmus; Oturduktan sonra Turk milletinin olkesini, toresini idare etmis, duzenlemiş. 
yüzyıllardan beri gelen töre hükümleri herkes tarafindan bilinmekte ve kayıtsızşartsız uyulmaktadır. Töre hükümlerine aykırı davrananlar en şiddetli biçimde cezalandırılılardı. Bozulan töreyi düzeltmek Türk kaganlarının en belli-başłı vazifelerinden birisidir: İlig tutıp, törüg itmis ${ }^{30}$. IIIteriş de dağınıklık içerisindeki ülkesini derleyip topladıktan sonra, bozulan töreleri düzenlemiştir: ilsiremiş, kagansıramış bodunıg küngedmiş, kuladmış bodunıg Türk törüsin ıçgınmış bodunıg eçüm apam törüsinçe yaratmış, boşgurmış ${ }^{31}$. Bilge Kagan, kendi milletinin tabi olduğu kanunları, idaresi altına aldığı milletlere de beyan etmiş vr bu hükümlere onların da uymasını istemiş̧ir: Bödke özim olurıp bunça agır törüg tört bulungdakı (bodun yayndım) ${ }^{32}$. $\mathrm{O}$, aynı zamanda, ihtiyaç hasıl oldukça tơre hükümlerini de yenilemiştir: Elig, törüg yegedi, kazgantım ${ }^{33}$.

Kaganlar töreyi düzenleyebilirler, fakat töre hükümlerini de tamamen ortadan kaldırmaya yetkileri yoktur. Bunun en güzel örneği Işbara Kagan (581587) zamanında yaşanan bir hadisedir. Bilindiģi gibi Işbara Kagan'ın zamanı tabi felaketler, savaşlar ve isyanlarla geçmiştir. Bu zor durum karşısında Işbara, Çin'in himayesini istemiş, Çin'de buna karşıllk olarak ondan, Türklerin Çin adetlerine dönmesini talep etmiştir. O da Çin'e yazdığı mektupta; "bizim adet ve geleneklerimiz çok eski çağlardan beri gelmektedir. Bundan dolayı onları değiştirmeye benim gücüm yetmez" diye cevap vermiştir ${ }^{34}$.

Kitabelerde geçen törüg kavramı, kanun manasına gelmektedir ${ }^{35}$. Bilindiği gibi, Türk düşüncesinde önemli bir yer teşkil eden otoriter devlet anlayışının iki dayanağından biri töreye sıkıca bağlıık, biri de devlet kuruluşlarının işleyişine damgasını vuran bu nizamda dikkatli ısrardır. Eski Türk yazıtlarında, Türk töresi halka ve gelecek nesillere anlatılmaktadır. Çin kaynakları da, Türk töresi hakkında uzun uzadıya bilgiler vermektedir ${ }^{36}$. Kanunlardan mahrum bir devletin yaşayabilmesi düşünülemez.

Kaganın bir başka görevi de, ullkeyi iktisaden refaha ulaştırmaktır. Milletin karnın doyurmak, üzerini giydirmek, milleti zengin yapmak kaganın

${ }^{30}$ Bakınız. Köl Tigin Yazıtı. Doğu, 3-4: Bilge Kagan Yazıtı. Doğı. 4-5: Ülkeyi tutup, töreyi düzenlemiş.

"Bakınız. Kol Tigin Yazztı. Dog̣u. 13-14: Blge Kagan Yazıtı, 4-5: Itsizlcşmiş. kagansızlaşmıs haikı, cariye olmuş. kul olmuş hatkı. Turk toresini kaybetmis milleti atalarımın toresince vücuda getirmiş, yetiştirmiş.

:2 Bakınız. Bilge Kagan Yazıtı, Doğu. 2: Bu zamanda kendim oturup, bunca onemli töreyi dört taraftaki halka yaydım.

"Bakımı. Bilge Kagan Y'szıtı. Doğu. 36: (Hheyi, toreyi çok iyi kazandım.

"Ogel, Tiurkierde Devlet.... s.312-313.

"Ci̊ğatiy, a.g.m.. s.279: A Inan, "Yasa. Tore-Ture ve Scriat". Türk Külturü Araștırmaları. 1/1. Ankara 1964, s. 104: A. Donuk. "Istamiyet ten Once Turklerde Devlet Adamı Tipi". Tlirk Kiiltürü, 24/275, Ankara 1986. s. 146

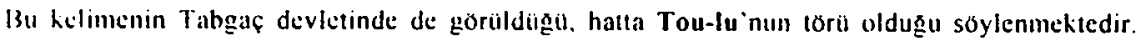
Bakiniz, Boodherg. H.g.m.. s. 17 1

") Ogel, a.g.e., s.130-131; Ogel, Türk Kültürünün Gclişme... s.113: Donuk. a.g.m., s. 146 
vazifesidir. Eğer bunlar gerçekleştirilemezse ülkede istikrar olmaz. Bu günümüz devletleri ve toplumları için de geçerlidir. Kapgan Kagan'ın gayelerinin başında ülkeyi yükseltmek ve milleti zengin etmek gelıniştir: Çıgany̧ı bay kıltı, azıg öküş kıltı ${ }^{37}$. Bilge Kagan tahta oturunca aç ve fakir bir şekilde etrafa dağılmış olan milleti bir araya getirerek zengin etıniştir: Çıany bodınıg bay kıltım. ${ }^{38}$ Yalıng bodunıg tonlıg kılıım. Cıgany bodunıg bay kıltım. ${ }^{39}$ Başlangıçta Türk devletinin iktisaden ayakta durması akınlar sayesinde oluyordu, fakat akın ve yağma ile bir devletin ayakta duramayacağın bilen Türk idareciler, devlet ekonomisini ve hayatını idarme ettirecek yeni yollar aramışlardır. Bilindiģi üzere, Türk ekonomisinin temeli hayvancıliga dayanmakla beraber, tarım ve ticarete de büyük önem verilmiştir. Daha Bumın devrinde, Kök Türklerin Çin sınırlarında ticaret yaptıklarını, Kapgan Kagan'ın Çin'den tarım araç ve gereçleri aldığını biliyoruz. ${ }^{40}$ Bilge Kagan halkının herşeyin en iyisine sahip olduğunu, kitabesinde söylemektedir: Sarıg altunın, ürüng kümüş̧in, kırgaglıg kutayın, kinlig işgitisin, özlük atın, adgırın, kara kişin, kök teyengin Türküme bodunıma kazganu birtim. ${ }^{41}$ Öyle ki, Bilge Basmıllar kervan göndermediler diye de sefer düzenlemiştir: Basmıl ıduk kut oguşım bodun erti. Arkış ıdmaz tiyin süledim. ${ }^{42} 703$ yllındaki bu seferin bir sebebi de, ülkenin ekonomisinin zarara uğramaması içindir. Büyük devlet ve büyük devlet adamı olmanın kurallarından birisi vatandaşını en iyi yaşatmaktır.

Kagan milletinin adını yükseltmelidir. Eğer ortada bir devlet var ise doğudan batıya, kuzeyden güneye dört yandaki herkes onun varlığından haberdar olmalıdır. Bilge Kagan kardeşi Köl Tigin ile birlikte, milletinin ve ullkesinin adını yükseltmek için gece gündüz çalışmıştır: Eçümiz kazganmış bodun atı küsi yok bolmazun tiyin, Tưrk bodun üçün udımadım, küntüz olurmadım. İnim Köl Tigin birle eki şad birle ölü yitü kazgantım. ${ }^{43}$

\footnotetext{
${ }^{37}$ Bakınız, Bilge Kagan Yazıtı. Dog̨u, 17: Fakiri zengin yapu, azı cok yapu

3k Bakını, Bilge Kagan Yazıtı. Kuzcy, 8: Kbl Tigin Yazıtı. Gimey, 10: Fakir milleti zengin yaptım

34) Bakını.. Köl Tigin Yazıtı, Doğu. 29: Bilge Kagan Yazıtı. Doğu. 24: Coplak millleti cibiscli yaptum. Fakir milleti zengin yaptım

4" Ogel. a.g.e., s.586: I. Katesoglu, Türk Milli Kultura. 2. baskı. Istanbul 1983. s.304-314: W. Eherhard, "Toba'ların Hayvancilıgi”. Belleten. C.9. Ankara 1945, s.486-192; Chang. a.g.t.. s. 155 .

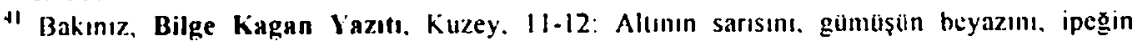
kenarlısını. desenli kumaşını, hususi atını, aygırını. kara samurumu, mavi sincabmı benim Turk milletime kazandın.

12 Bakını, Bilge Kagan Y'azıtı, Dogu, 25: Básmıllar, kutłu soyumdan halk idi. Kervan göndermiyor diye ordu sevkettim.

43 Bakınız. Köl Tigin Yazıtı, Doğu, 27: Bilgc Kagan Yazıtı. Doğu, 22: Atalarımızın kazannıs olduğ milletin adı. unä yok olmasın diye. Türk milleti için gece nyumadım. gúndiz oturnadım. Küçitk kardeşim kol Tigen ile iki sad ile obley yte karandom.
} 
Türk kaganları, yaptıkları işleri ve gelecekte karşılaşılabilecek durumları daha sonraki nesillere bildirmişlerdir. Büyük devlet olmanın gereği, baştaki yöneticinin ve hükümetin vatandaşlarına yapılan işleri bildirmesi, bunların gelecek nesillerce de öğrenilmesini sağlamaktır. Bu sebeple, büyük Türk kaganlarının hepsinin bir yazıtı mevcuttur. Gerçi, bunların çoğu daha gün ışığına çıkmayı bekliyorlar, fakat elde bulunanlar da Türk ve dünya tarihi için, çok büyük önemlere haizdir.

Büyük devlet adamı Bilge Kagan, kardeşi Köl Tigin için Çin'den getirttiği sanaatkârlar ve Yolıg Tigin'in çabalarıyla diktirdiği kitabede babası ve amcası zamanındaki olayları anlattığı gibi, daha önceki hadiselerden de haber vermiştir: Tabgaç kaganta bedizçi kelürtim, bediztim. Mening sabımın sımadı. Tabgaç kaganıng içreki bedizçig ıtdı. Angar adınçıg bark yaraturtdım. ỵçin taşın adınçıg bediz urturtdım, taş tokıtdım. Köngüldeki sabımın...On Ok oglınga, tatınga tegi bunı körü biling. Bengü taş tokıtdım...erig yirte irser ança erig yirte bengü taş tokıtdım, bitidim. Anı körüp ança biling. ${ }^{44}$ Bilge'den sonra oglu da babasının yazıtını dikerek, bir yerde milletine ve geleceğe hesap vermekle beraber, ögütlerde de bulunmuştur. Zaten yazıtların en önemli tarafı da budur.

Kök Türklerden sonra iktidar mevkiine geçen, Uygur kaganları da aynı şekilde davranmışlardır. Moyun Çor da kendi adına iki kitabe yazdırmıştır: Iduk Baş kidinte Yabaş, Tokuş beltirinte anta yayladım. Örgin anta yaratıtdım. Çıt anta tokıtdım. Bin yıllık, tümen künlik bitigimin, belgümin anta yası taşka yaratıtdım. ${ }^{45}$ Moyun Çor'un oğlu Bögü de, devrinde yazıtlar diktirmiştir. Bunlardan Tes II, Kök Türkçe olduğu gibi, Sevrey yazıtı da Sogdçadır. Hem Kök Türkçe, hem Çince, hem de.Sogdça yazılan Karabalgasun yazıtı da, Uygur tarihini ihtiva etmektedir ve Küçlüg Bilge Kagan (821-824) zamanında yazılmıştır. Burada da kaganların faziletlerinden bahsedilmektedir.

Bunun yanısıra, çeşitli boy beyleri ve komutanlarda kendi kitabelerini yazarak kendinden sonra geleceklere miras bırakmışlardır.

Kaganlık müessesesi ve kaganın vazifeleri daha sonraki yüzyıllarda, özellikle Kutadgu Bilig'de çok iyi bir şekilde anlatılmıştır. Nasıl kaganın milletine karşı vazifeleri var ise, milletin de devletine ve kaganına karşı vazifeleri

\footnotetext{
th Bakını, Köl Tigin Yazıtı, Güney, 11-13; Bilge Kagan Yazıtı, Kuzcy, 14: Çin imparatorundan nakı\$̧ı getirttim, süslettirdim. Benim souzümü kırmadı. Cin imparatoru saray nakış̧ısını gönderdi. Bunlara ayı bir bark yaptırdım. İçine, dısına deģişik sủs yaptırdım, taş yontturdum, Gonüldeki sozumü (yazdırdım). On Ok ogulları ve yabancılara kadar herkes bunu gorup bilsin! Ebedi taş yontturdum. Corak yerde ise, bőylece forak yerde ebedi taşı yontturdum, yazdırdım. Onu görüp böylece bilin.

45 Bakınız, Sine-Llsu Yazıtı, Doğu, 9-10: Taryat-Terhin Yazıtı. Batı, 2: Iduk Baş'ın batısında Yabas ve Tokus un kavşą̧ında orada yazı geçirdim. Otağımı orada yaptırdım. Sınırı orada yaptırdım. Bin yıllık, onbin günlük yazıtımı ve işaretımi orada yassı taşa yaptırdım.
} 
vardır. Herkes üzerine düşen görevi yerine getirmek zorundadır. Devletin var olması ve devam edebilmesi buna bağlıdır.

Türk devletinde kagandan sonra ikinci sırayı katun ${ }^{46}$ almaktadır. Günümüz Türkçesinde bu adı kadın şeklinde görmekteyiz.

Katunlar, kaganlar gibi töre ile katunluk tahtına oturuy orlar $^{47}$ ve kagan ile beraber hükümet ediyorlardı: Türk bodun yok bolmazun tiyin, bodun bolçun tiyin kangım ilteriş Kaganıg, ögüm il Bilge Katunıg töpüsinte tutıp yügerü kötürmiş erinç. ${ }^{48}$ Özellikle Katunların Kaganlarla birlikte tayin edilmeleri hadisesi Uygur kitabelerinde sıkça geçmektedir. Uygurların ünlü kaganı Moyun Çor, kardeşi Tay Bilge Tutuk'u ortadan kaldırdıktan sonra, katunu ile birlikte hükümranlık tahtına oturmuştur: Tengride Bolmış il Etmiş Bilge Kagan atadı, il Bilge Katun atadı. ${ }^{49}$ Katunların tahta çıkışları da tıpkı kaganlar gibi bir merasimle olmaktadır. 822 senesinde Uygur kaganı Küçlüg Bilge (821-824) için gönderilen Çinli konçuyun Uygur başkentine gelişi ve ona yapılan törenler Çin kaynaklarında çok renkli bir şekilde anlatı/mıştır: Konçuyu Uygur katunluğuna tayin için uğurlu gün seçilmiştir. Kagan önce kulesine çıarak, doğuya dönmüştür. Kulenin altında, prenses için büyük bir keçe çadır kurdurmuştu. Bir grup insan Çinli elbiselerini çıkarıp, Uygur elbiselerini giyerler. Konçuy her ikisi de kırmızı olan renkli bir eltise ve büyük bir manto ile altın işlemeli bir başlık giymişti. O, kuleye doğru dışarı çıkıp, kaganı selamlamıştı. Uygurlar, küçük bir taht tanzim etmişler, dalgalı perdeli bir tahtırevan hazırlamışlardı. Bazı bakanlar prensesi tahtırevana bindirdiler. Dokuz Uygur kabilesinin herbirinin buşkanı tahtırevanı taşıdılar. Güneşi takip ederek, sarayın etrafında dokuz defá döndüler. Sonra prenses, tahtırevandan indi. Kuleye gitti. Doğuya dönülk olarak kaganla birlikte oturdu. Ondan sonra, bakanlar ve yardımcılar kagan ve katuna hürmetlerini bildirmişlerdir. ${ }^{50}$ Türk kültür tarihi için oldukça ónemli olan bu kayıtlara göre, katunun da kendi sarayı olduğu söylenmektedir.

4h Katun unvanının Tu-yu-hun, Sogd ve Mogollara dayandırıldığ (bakınız, Clauosn, a.g.c.. s.602; A. Donuk, Eski Türk Devletinde Idari ve Askeri Unvan ve Terimler, İstanbul 1988 , s.30; Boodberg. a.g.m., s.170), bununla birlikte Hunlar çă̆ından beri bilinen bu unvanın Turkçeleştiğ ve Turkleştiğ kabûl edilmiştir (bakınız. Katesoğlu, a.g.e., s.257).

$47 \mathrm{C}$. Mackerras. The Uighur Empire. According to the T'ang Dynastic Histories, Canberra 1972. s.120; E. Esin. The Culture of the Turks: The Initial Inner Asia Phase. Ankara 1986. s.9; Laszlo, a.g.m., s.47: G. Candarlıoglu;, "Turk Toplumunda Kadın”, Hayat Tarih Mecmuası, 1/4, Istanbul 1966, s.22; W.S. Tsai, Li Te-Ya'nün Mektuplarına Göre Uygurlar (840-900), Doktora Tezi, Taipei 1967, s.8-9

4x Bakınız, Köl Tigin Yazıtı, Doğu, 10-11; Bilge Kagan Yazıtı, Dogu, 10:Turk milleti yok olmasin diye, millet olsun diye babam Ilteris Kagan's ve annem II Bilge Katun'u (Tanrı) halk içerisinden çekip yukseltmiştir.

${ }^{44}$ Bakınız, Taryat-Terhin Yazitı. Guney, 6.

${ }^{301}$ Mackerras, a.g.e., s.120; Tsai, a.g.t., s.8-9. 
Tarihte Türk kaganlannın bir iki kez evlendiklerini, fakat bunlardan sadece birisinin baş hatun olduğunu biliyoruz. Bunun neticesi olarak yalnız Türk soyundan olan katunların çocukları veliaht olabiliyorlardı. ${ }^{51}$ Kagan öldüğü zaman, yerine geçecek olan çocugu küçük ise, o zaman katunun devleti oğlu adına yönettiğini de görüyoruz. Bunun örneklerine Kök Türkler, Selçuklular ve Osmanlılar gibi büyük Türk devletlerinde rastlanmaktadır.

Savaşlarda da katunların, kaganların yanında yer aldıkları görülmektedir. 743 senesinde Moyun Çor, Ozınıs Tigin ile yapmıs olduğu savaşta, katununu da esir alımıştır: Ozınş Tigin kan bolmış. Koyn yılka yorıdın. ÿkinti süngüs engilki ay altı yangıka tokıdım...tutdım. Katunın anta altım. Türk bodun anta ıngaru yok boltı. $^{\text {s? }}$

Katunların devlet meclislerine katıldıklarını ve oy sahibi olduklarını da biliyoruz. 725 de, Çin'den gelen elçiyi karşılayan heyet arasında Bilge Kagan'ın karısı Po-fu Katun da yer almıştır. ${ }^{\text {s: }}$

Netice olarak, kagan ve katunluk özelliklerini taşımayanlardan Tanrı kutlarını aldığı gibi, bu kişiler görevlerini yerine getirmediği takdirde de iktidardan uzaklaştırılıyorlardı.

\footnotetext{
"Liu, a.g.e., s.43-44: Ögel, H.g.e., s.448: Ecsdy, a.g.m., s.251.

$\$ 2$ Bakınız, Sine-l/su Yazıtı, Kuzey, 9-10; Taryat-Terhin Yazıtı, Dogu, 9; Gưney. 1: Ozmı\$ Tigin han olmuş. Koyun yılında (743) lizerine yürudüm. IKinci savaşı ilk ayın altıncı gunande yaptm .. tutdum. Katununu orada aldım. Türk milleti o andan itibaren yok oldu.

53 Liu, a.g.e. 5.226-227; Chang. a.g.t., s.117; C. H. Huang.
} 